\section{CLINICAL LECTURE}

\author{
ON A CASE OP
}

\author{
COMMINUTED FRACTURE OF THE CLAVICLE, \\ WITH COMPRESSION OF THE SUBCLAVIAN \\ VEIN BY ONE OF THE FRAGMENTS. \\ Deliverid at Uiniz'rsity College Hospital, London. \\ BY JOHN ERICHSEN, F.R.C.S., \\ Surgeon to the Hospital, and Holme Professor of Clinical Surgery.
}

Gentlemen, - The case to which I wish to direct your attention to-day is one of a comminuted fracture of the clavicle from direct violence, accompanied by compression of the subclavian vein by one of the fragments, which resulted in gangrene of the arm.

William Anstis, aged 27, a married man, who had always enjoyed a good health, and was of temperate habits, whilst assisting in moving some timber, received a severe blow, from a large mass of it falling on his shoulder, on Thursday, March 2oth, 1873; and, finding the arm powerless, he applied to a medical man, who adjusted a sling, and sent him to University College Hospital. There it was found that the clavicle was broken and comminuted about the middle; several movable and depressed fragments being felt beneath the skin. As some fulness of the veins was noticed, the fingers and thumb were separately enclosed in a bandage, and this was carried up the forearm and arm as high as the insertion of the deltoid, after previously flexing the elbow. A pad made of tow covered by a bandage was then placed in the axilla, and the arm was fixed to the side by turns of a roller applied round the body, and was then supported by a sling. He left the hospital at 7 P.M., with injunctions to come again on Saturday morning, if all remained comfortable, but immediately if any uneasiness occurred in the limb. $\mathrm{He}$ walked home, and after going to bed at Io P.M. passed a pretty good night, though feeling some pain at the seat of fracture ; but on Friday, March 2 Ist, about noon, the arm began to swell, and at some parts, where the turns did not quite meet, he noticed bullæ, which burst during the evening, discharging a bloody serum and leaving the skin of a dark purple colour beneath them. The fingers soon became numb and cold, and this feeling extended to the arm, in which there was sufficient pain to prevent sleep that night; nevertheless, he did not return to the hospital till Saturday, the 22nd, at noon, or forty-one hours after leaving it.

On removing the bandage, a dark purple discolouration was seen to extend from the fingers to the axilla, mottled here and there with paler and redder patches, and scattered over the surface were numerous bullæ, some of which contained a yellow, and others a dark purple serum. There was no sign of constriction at the elbow, and no tension of the skin, and, though somewhat odematous and doughy to the touch, the limb was about of normal size. It was distinctly colder than the other, and there was no sensibility in the fingers and no power of localising sensations in the forearm. No change of colour took place on squeezing the finger-nails, and the thumb was almost white, but the circulation was still present in other parts.

He was immediately put to bed, the arm being supported on a pillow above the level of the shoulder, and loosely wrapped in cotton-wool. No material change took place during the first few hours after admission, but in the course of the evening the whole limb began to swell with extreme rapidity, while fresh bullæ appeared on the surface; the parts in the neighbourhood of the elbow soon reached nearly double the natural size, so that a bandage which had been loosely applied over some cottonwool, became tense, and had to be released.

At II.3O P.M., I was called to see him on account of the formidable rapidity of the swelling, and, after chloroform had been administered, I made twelve incisions, each of which was from one and a half to two inches in length in the part where the tension was greatest (i.e., from four inches below the elbow to the insertion of the deltoid), but confining them to the aspect of extension of the limb; hot fomentations were then applied over the area occupied by the incision, while the rest of the forearm and hand were enclosed in cotton-wool.

During the next two days the patient's general condition was not unfavourable, his appetite remaining fairly good and his tongue moist; but, though the strangulation of the arm had been relieved by the in cisions, the left hand remained distinctly colder than the right, and on the 24th it was doubtful if there was any heat in it that could not be accounted for by the warmth of the fomentations. No change of colour occurred on pressing the fingers and hand; and, though it was evident that some circulation remained in parts of the forearm, an indefinite line of separation appeared to be forming three inches below the elbow, while above this the parts remained in a state of acute inflammation, and there was apparently no sensibility below the insertion of the deltoid, at which level there was a somewhat abrupt limit to the inflamed area.

During the next fortnight there was no very marked alteration in the patient's constitutional condition; he continued to take his food well, and, with the assistance of an occasional opiate, slept moderately, and there was a gradual fall of pulse and temperature, followed, however, at last by a somewhat sudden rise. In the forearm sloughs of large size became apparent, their edges being sharply defined from the rest of the skin, which was now much inflamed and very brawny and œdematous; and from beneath them, as well as from the incisions, there was a copious discharge of very offensive pus, the emanations from which were corrected as much as possible by oakum poultices frequently changed. The largest of these sloughs involved almost the whole of the skin of the front of the forearm; and on its separation it was seen that all the superficial muscles had broken down into a yellow pasty material, amongst which the radial artery and median nerve were freely exposed for several inches. The tips of the fingers became dry and black, but, strange to say, circulation returned in the skin at the back of the hand and proximal phalanges of the fingers.

On March 31st, rather copious hæmorrhage occurred from a vein of some size in one of the incisions, which was promptly arrested by $\mathrm{Mr}$. Skerritt, the house-surgeon, by ligaturing both ends of the vessel.

On April 3rd, two more incisions were made by Mr. Hill, who took charge of the case in my absence, in the brawny tissue about the elbow; and on April 6th, the inflammation in the arm having by this time somewhat subsided, and imperfect sensibility having returned to within an inch of the elbow, it appeared that the most suitable period for am putation had arrived; and this was accordingly performed by Mr. Hill, who removed the limb at the shoulder-joint. The flaps were extremely vascular, and a large number of whip-cord ligatures were applied; they were brought together by silver wire sutures, and the stump was dressed with dry lint fixed in position by a bandage.

An examination of the limb after removal showed more or less com. plete destruction of all the muscles of the forearm, and of all the tissues beneath the skin in the hand, while separate gangrenous patches existed in the lower part of the triceps and brachialis anticus; and there was necrosis of part of the ulna, and one or two of the metacarpal bones. The vessels presented a quite normal appearance, except only where they had come into contact with the sloughs.

On the day after the operation there was a transitory rise of temperature, but the general health seemed but little affected, and the stump promised to do exceedingly well. But on April roth, a prolonged rigor occurred, and very soon unmistakable symptoms of pyæmia set in, which ran a typical course; and, together with the effects of some secondary hæmorrhage on April I6th, which necessitated the opening up of the flaps, terminated the patient's life on the morning of A pril I 7 th.

Post Mortem Examination.-A large and abominably fotid clot was found in the wound, extending downwards into the axilla and upwards into a cavity beneath the coracoid process ; and, on cutting down on the clavicle, the ends of the fractured bone, which were extensively comminuted, were seen to lie in the sac of an abscess, but whether this communicated or not with the cavity of the wound was not accurately ascertained. The nature of the fracture was remarkable. The anterior surface of the bone was broken across irregularly at a distance of

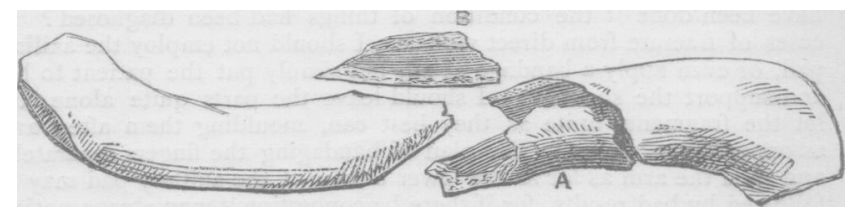

two-and-a-half inches from the acromial end; and a splinter (A), one inch long, almost separated from the outer fragment, lay in front of the inner one. But at this point also a piece of bone (B), one-and-a-half inch long, and in thickness about equal to half that of the clavicle, had been split off from the posterior aspect, and occupied exactly the position of the subclavian vein, upon which it must have inevitably exercised considerable pressure, when the arm assumed the position which is almost invariable after fracture of this bone. No bruising or injury of the vein was, however, to be discovered at this point ; but it must be remembered that twenty-eight days had elapsed since the time of the accident. The lower part of the vein presented a soft clot, which was suppurating and breaking down; and numerous secondary abscesses existed in the lungs. 
The clavicle, from its position as the only bony communication between the upper limb and the body, is most frequently broken by violence indirectly applied during the transmission, through it, of the shock which is caused by a fall on the hand or shoulder. Under such circumstances, it generally gives way near the great convexity, and the fracture is usually oblique, and almost always simple, while the subjacent structures escape without injury ; but when, as in the present case, the bone is broken by direct violence, the fracture may be transverse, or comminuted, or both, and any amount of damage may be done to the parts beneath. The most common form of injury which it may give rise to is compression or laceration of the subclavian vein-the latter being exceedingly rare, though a case of the kind occurred in this hospital some years ago, and, as is well known, the late Sir Robert Peel died of this accident. The artery appears always to escape. I know of no case in which it has suffered (if gunshot injuries be excluded); but the brachial plexus has been interfered with, the first rib has been fractured, and laceration of the pleura has taken place.

Here the fracture was undoubtedly caused by direct violence. It was put up in the usual way, but on the next day the arm began to swell beneath the bandages; and before forty-eight hours had elapsed from the time of injury, it was much swollen and very oedematous, and threatening gangrene. For this condition of things two explanations are possible. I. The subclavian vein had been contused or lacerated; 2. The axillary pad and bandage had been too tightly applied. And, after careful examination, it appeared that the mischief was most probably the result of some injury of the vein, while at the same time there was no sufficient ground for thinking that it could be due to any fault of the apparatus applied, and that for the following reasons.

I. There was no evidence that the bandage was too tight.

2. It was quite certain that the elbow was flexed before the arm was bandaged.

3. The axillary pad was unusually soft ; and I must add that, though harder ones are commonly used, I have never seen any mischief result from their employment.

One of the most remarkable features of the case is, that although on admission there was a condition approaching to gangrene, yet there was no very great amount of swelling until the arm had been entirely liberated for some hours, when it became so excessive that the bandage, loosely applied over some cotton-wool, had to be released. This state of the limb might have been brought about in either of the following ways.

I. If the subclavian vein had been compressed, irritated and plugged, it is clear that no great amount of swelling could occur from the obstruction of the return of blood to the limb until the enclosing bandage was removed.

2. A sort of inflammatory œedema may have extended through the limb, something like that which occurs in traumatic gangrene; and I am disposed to think that such was the case here-a kind of cellulitis setting in, with great effusion of sero-plastic fluid, and tension of the skin ; for, in the first place, the swelling was very extensive above the elbow, where there was no retardation to the blood-flow; and, secondly, on making the incisions, the cellular tissue was found to be much infiltrated with serous fluid, without any very remarkable distension of the veins; but, with the view of avoiding the latter as much as possible, the incisions were confined almost entirely to the outer aspect of the limb.

This case serves to illustrate a particular danger that may follow fracture of the clavicle; and the question presents itself, What ought to have been done if the condition of things had been diagnosed? In cases of fracture from direct violence, I should not employ the axillary pad, or even apply a bandage at all, but simply put the patient to bed and support the shoulder. I should leave the parts quite alone, and let the fragments unite as they best can, moulding them afterwards as opportunity offered. The plan of bandaging the fingers separately, and then the arm as far as the lower border of the axillary pad may be followed by bad results, for if there be congestion it may escape notice, and such congestion may go so far as to strangle the limb under the bandage. If, then, the fingers, hand, and forearm be bandaged at all, it should be done lightly and openly, so that you may not be prevented from seeing what is taking place in the limb.

Royal College of Surgeons in Ireland.-At a meeting held on Monday, June 2nd, I873, the following officers were elected :President: John Denham. Vice-President: Robert W. Smith. Secretary to the College: William Colles. Conncil: R. Adams, W. Colles, F. Kirkpatrick, Richard G. H. Butcher, Alfred H. McClintock, Alexander Carte, G. H. Porter, J. H. Wharton, B. McDowel, A. J. Walsh, E. Hamilton, E. Ledwich, R. Macnamara, R. McDonnell, J. Morgan, G. H. Kidd, E. D. Mapother, A. H. Jacob, H. G. Croly.

\section{THE ACTION OF DRUGS AND OTHER MEDICINAL AGENTS UPON THE TISSUES OF THE LOWER ORGANISMS.}

By W. AINSLIE HOLLIS, M.D.,

Medical Registrar and Casualty Physician to St. Bartholomew's Hospital.

$$
\text { I. }
$$

A SHORT time has only elapsed since the publication of three valuable series of lectures illustrating the action of drugs on the animal economy. Two of these courses have been, or, I may perhaps say, still are being, published at intervals in this JoURNAL-I allude to those by Drs. Brunton and Fraser (see JoURNAL for 1871 and 1872 ) ; the third has appeared in the pages of a contemporary from the pen of Dr. Rutherford. It is with some diffidence that I commence a series of papers on what may, at first sight, appear to be exhaustively treated by one or other of the above-named gentlemen ; but I hope, however, to show that I shall not seriously encroach on the subject matter investigated by them, inasmuch as my experiments will be strictly confined to the invertebrate animals, and specially to the operation of medicinal agents on those lowly organised beings in whom the energy inherent in their plasma is untrammelled by nervous or vascular influence. Since the valuable treatise of Kühne (Untersuchungen über das Protoplasma, Leipzig, 1864) has been published, Binz, Stricker, Recklinghausen, Cohnheim, and others, have investigated the action of certain drugs on different forms of amœboid life; and lately Rossbach (Die Rhythmische Bewegungs. erscheinungen der einfachsten Organismen. Verhand. der Physik-med. Gesellsch. Würzburg, 1872) has carefully recorded his observations of heat and various chemico-physical agents on the movements of the contractile vesicles and cilia of certain infusoria and vorticellæ. In the following researches, my constant aim has been to elucidate by experiments the molecular changes which may occur after the exhibition of medicinal agents in the tissues of animals, irrespective of any influence induced by the operation of nervous or vascular systems. With such views before me, I shall attempt in each case to show the action of the peculiar agent employed ; first, upon the vitalised, and to some extent independent, components of the animal under observation; secondly, its action upon the animal itself. By this method I hope to eliminate those operations which depend on the mutual relations of the various components of an organised mass from those which are unconnected with any such dependence; at the same time that we ascertain the connection (if any) which exists between the molecular changes of the components and the functional or other phenomena of the aggregates.

In order fully to illustrate this inductive method of observation, $I$ have selected for the first series of experiments the lowly organised actinia; and this has been done partly from the readiness with which such animals can be examined during the course of the investigations upon them, and partly from the great persistence of life exhibited by their component molecules (Fournal of Anatomy, vi, p. 382) when removed from the body, as this property permits the exhibition of various chemical agents to them without destruction to their life.

The first experiments noticed will show the effect of increments of temperature on the above-named organisms, both as respecting their molecular constituents and in the aggregate. They were made on the pulsatile corpuscles, elsewhere described by me (Ibid.), and were performed with the assistance of a modification of Stricker's hot stage (kindly lent to me by my friend Dr. Lauder Brunton), a spirit-lamp, and a microscope. The results are tabulated.

Table I. - Application of Heat to the Pulsatile Corpuscles of Actiniae.

\begin{tabular}{r|l|l}
\hline $\begin{array}{c}\text { Degrees. } \\
\text { Cent. }\end{array}$ & \multicolumn{1}{|c|}{ a. Pulsations in 10" } & \multicolumn{1}{|c}{$b$ Pulsations in 10" } \\
\hline 5 & & 18 \\
10 & 78 (strength increased) & 20 \\
15 & 184 & 23 \\
18 & 24 (feeble) & 26 \\
20 & 28 ? (feelle & $30 ?$ (feeble). \\
23 & Very feeble & $32 ?$ \\
24 & None & 35 ? \\
25 & & A tremor; motion almost ceased. \\
28 & &
\end{tabular}

The results in the third column of the table were obtained from the pulsations of a corpuscle extracted from a more vigorous actinia than

* The rapidity of the pulsations above 26 in $\mathrm{IO}^{\prime \prime}$ is so great that it may be doubted whether the subsequent numbers are correct. Practice has, however, enabled me to place the contractions with tolerable, if not perfect, certainty, as recorded. 